OPEN ACCESS

Edited by: Junlei Chang,

Shenzhen Institutes of Advanced Technology, Chinese Academy of Sciences (CAS), China

Reviewed by:

Xinchun Jin

Capital Medical University, China

Xia Li,

Fourth Military Medical University,

China

*Correspondence:

Wen-Bin Liang

wlian3@uottawa.ca

Hong-Fei Zhang

zhanghongfei@smu.edu.cn

${ }^{t}$ These authors have contributed equally to this work and share first authorship

Specialty section: This article was submitted to Multiple Sclerosis and

Neuroimmunology,

a section of the journal

Frontiers in Immunology

Received: 06 July 2021 Accepted: 06 August 2021

Published: 27 August 2021

Citation:

Lin H-B, Li F-X, Zhang J-Y, You Z-J, $X U S-Y$, Liang $W-B$ and Zhang $H-F$ (2021) Cerebral-Cardiac Syndrome and Diabetes: Cardiac Damage After Ischemic Stroke in Diabetic State.

Front. Immunol. 12:737170. doi: 10.3389/fimmu.2021.737170

\section{Cerebral-Cardiac Syndrome and Diabetes: Cardiac Damage After Ischemic Stroke in Diabetic State}

\author{
Hong-Bin Lin ${ }^{1+}$, Feng-Xian $\mathrm{Li}^{1+}$, Jin-Yu Zhang ${ }^{2}$, Zhi-Jian You ${ }^{3}$, Shi-Yuan Xu ${ }^{1}$, \\ Wen-Bin Liang ${ }^{4 *}$ and Hong-Fei Zhang ${ }^{1 *}$
}

\begin{abstract}
${ }^{1}$ Department of Anesthesiology, Zhujiang Hospital of Southern Medical University, Guangzhou, China, ${ }^{2}$ State Key Laboratory of Ophthalmology, Zhongshan Ophthalmic Center, Sun Yat-sen University, Guangzhou, China, ${ }^{3}$ Guangxi Health Commission Key Laboratory of Clinical Biotechnology, Liuzhou People's Hospital, Liuzhou, China, ${ }^{4}$ University of Ottawa Heart Institute and Department of Cellular and Molecular Medicine, University of Ottawa, Ottawa, ON, Canada
\end{abstract}

Cerebral-cardiac syndrome (CCS) refers to cardiac dysfunction following varying brain injuries. Ischemic stroke is strongly evidenced to induce CCS characterizing as arrhythmia, myocardial damage, and heart failure. CCS is attributed to be the second leading cause of death in the post-stroke stage; however, the responsible mechanisms are obscure. Studies indicated the possible mechanisms including insular cortex injury, autonomic imbalance, catecholamine surge, immune response, and systemic inflammation. Of note, the characteristics of the stroke population reveal a common comorbidity with diabetes. The close and causative correlation of diabetes and stroke directs the involvement of diabetes in CCS. Nevertheless, the role of diabetes and its corresponding molecular mechanisms in CCS have not been clarified. Here we conclude the features of CCS and the potential role of diabetes in CCS. Diabetes drives establish a "primed" inflammatory microenvironment and further induces severe systemic inflammation after stroke. The boosted inflammation is suspected to provoke cardiac pathological changes and hence exacerbate CCS. Importantly, as the key element of inflammation, NOD-like receptor pyrin domain containing 3 (NLRP3) inflammasome is indicated to play an important role in diabetes, stroke, and the sequential CCS. Overall, we characterize the corresponding role of diabetes in CCS and speculate a link of NLRP3 inflammasome between them.

Keywords: cerebral-cardiac syndrome, ischemic stroke, cardiac damage, NLRP3 inflammasome, diabetes mellitus

Abbreviations: CCS, Cerebral-Cardiac Syndrome; IS, Ischemic Stroke; ECG, Electrocardiograph; cTnI, Cardiac Troponin I; cTnT, Cardiac Troponin T; hs-cTnT, High-Sensitive Cardiac Troponin T; LVSD, Left Ventricular Systolic Dysfunction; HPA, Hypothalamus-Pituitary-Adrenal; PKA, Protein Kinase A; BBB, Blood-Brain Barrier; ROS, Reactive Oxygen Species; IL, Interleukin; CAN, Cardiac Autonomic Neuropathy; NLRP3, NOD-like receptor pyrin domain containing 3. 


\section{INTRODUCTION}

Cerebral-cardiac syndrome (CCS) is an interplay between the brain and the heart, which is also known as neurocardiogenic syndrome. Various brain injuries such as ischemic stroke (IS), intracerebral hemorrhage, subarachnoid hemorrhage, traumatic brain injury, and stress are evidenced to cause cardiac injuries or to exacerbate preexisting heart disease, which manifests as arrhythmia, various myocardial damages, heart failure, and myocardial infarction (1-5). CCS can be found after brain injury even without primary heart disease (6). However, it is more likely to occur in the context of cardiovascular and cerebrovascular diseases such as diabetes, hypertension, and obesity (7). IS is a common brain injury, and the consequence of cardiac complications contributes to a higher risk of death in the post-stroke stage (6). In the acute stage following IS, arrhythmias are the most common cardiac complications, while in the chronic stage, cardiac dysfunction, heart failure, myocardial fibrosis, and hypertrophy can also be detected (810). Of note, diabetes not only drives the incidence of cardiovascular and cerebrovascular comorbidity but also leads to poor prognosis afterward. However, the key molecular mechanisms and responsible pathways of the interaction of diabetes on CCS are unclear. Inflammation is an important trigger for both diabetes and CCS $(11,12)$, and NOD-like receptor pyrin domain containing 3 (NLRP3) inflammasome is the crucial element to promote the maturation and release of IL$1 \beta$ and IL-18 (13). Recent studies have indicated the role of NLRP3 inflammasome in diabetes and diabetic CCS $(14,15)$. Therefore, the responsible pathway of NLRP3 inflammasome activation and subsequent effects on diabetic CCS need further exploration.

CCS has now gained more attention due to the emerging impact of stroke on cardiac pathophysiological comorbidity. To further dissect the corresponding mechanisms, we herein review and summarize its clinical features, pathophysiological process, and the underlying molecular crosstalk. Furthermore, we summarize the special role and explain the underlying molecular mechanisms of diabetes in CCS. Lastly, we speculate a reasonable link of NLRP3 inflammasome between diabetes and CCS.

\section{CEREBRAL-CARDIAC SYNDROME IN ISCHEMIC STROKE}

\section{Clinical Features}

The prevalence of patients who died of cardiac complication after IS has been estimated to be about $4 \%-19 \%$ (16-18). Positive correlation has been indicated between cardiac complications and the severity of IS (19). Substantial evidence shows that IS provokes cardiac arrhythmias such as atrial fibrillation, ventricular ectopy, atrioventricular conduction disturbance, or nonsustained ventricular tachycardia (20). Most of the arrhythmias occur in the acute phase, with $93.9 \%$ onset in the first day after stroke (21). The most common type is atrial fibrillation, with an incidence rate of $10 \%$ within $24 \mathrm{~h}$ (22) and
$68.7 \%$ within $72 \mathrm{~h}$ of admission (8). Second- or third-degree atrioventricular conduction block, focal atrial tachycardia, and supraventricular tachycardia are also present. Preexisting cardiac disease is the major cause of newly diagnosed atrial fibrillation (23). Abnormal electrocardiograph (ECG) changes have also been reported in 65\%-69\% IS patients, including prolonged QT intervals (26\%-36\%), ST depression or elevation (24.5\%$50 \%$ ), and $\mathrm{T}$ wave inversion (17.8\%) (24-26). A prolonged QT interval has positive correlation with sudden cardiac death (27), while ST-segment changes predict early mortality (25). Stroke patients benefit from prolonged ECG monitoring, which is effective in detecting atrial fibrillation, particularly for those with elevated hs-cTnT levels and insular ischemia (28). However, it should be noted that more than two-thirds of patients did not receive 24-h Holter monitoring within 30 days of stroke or transient ischemic attack, and only less than $1 \%$ patient received prolonged 48-h ECG monitoring (29).

The incidence of several types of myocardial damage increased after IS. It was reported that $88 \%$ of patients with right insular cortex ischemia suffered from myocardial injury in the weeks after stroke (30). Kolin et al. found that focal transmural myocardial damage was significantly increased in stroke patients (62\%) (31). Myocardial infarction has been reported in $2.2 \%-4.9 \%$ of the stroke population $(32,33)$. Of note, for those without prior coronary artery disease, the incidence of myocardial infarction reaches $3.5 \%$ after IS (34). Besides, studies have reported that different myocardial enzymes elevated after IS, including cardiac troponin I (cTnI) [20.6\% (35)], cardiac troponin $\mathrm{T}$ (cTnT) [9.6\% (24)], high-sensitivity cardiac troponin T (hs-cTnT) [22.8\% (36)], and creatine kinase-MB (CKMB) $[34.4 \%$ (37)]. The increased myocardial enzymes, especially of hs-cTnT, are reliable indicators of myocardial damage and are useful in predicting poor outcomes after stroke (38). IS also induces cardiac dysfunction after myocardial damage. A total of 11.6\% patients have been suffering from left ventricular systolic dysfunction (LVSD) after IS (39). Neurogenic stunned myocardium can also be found after IS and manifests as reversible LVSD (40). In addition, a previous study has suggested that $91.3 \%$ of IS patients suffer from takotsubo cardiomyopathy, which is characterized by LVSD and abnormalities in myocardial enzymes and ECG (41). A study has shown that $17 \%$ of patients were diagnosed with decompensated heart failure after IS (42). Of note, impaired cardiac function can be a predictor of poor prognosis (39). IS patients with cardiac dysfunction have higher mortality and prolonged hospitalization than those without cardiac complications (43).

Overall, the clinical features of CCS include arrhythmia, ECG changes, various myocardial damages, and heart failure. We herein summarize the multiple manifestations of clinical cardiac damage and the correlated incidence after IS (Table 1). As the clinical features of CCS are documented to predict poor prognosis after stroke, it is possible to improve the prognosis and decrease the mortality of stroke by enhancing the diagnosis and initiating treatment for cardiac complications.

\section{Pathophysiological Mechanisms}

Clinical and experimental studies have explored the potential mechanisms of CCS. However, experimental animal studies 
TABLE 1 | Symptoms and incidence of cardiac complications after IS.

\begin{tabular}{|c|c|c|}
\hline Symptom & Type & Incidence \\
\hline \multirow[t]{9}{*}{$\begin{array}{l}\text { ECG } \\
\text { changes }\end{array}$} & Atrial fibrillation & $\begin{array}{l}\text { 10.0\% (within } 24 \text { h) (22), 17.2\% } \\
\text { (within } 72 \text { h) (8) }\end{array}$ \\
\hline & Focal atrial tachycardia & 2.9\% (within 72 h) (8) \\
\hline & $\begin{array}{l}\text { Second- or third-degree } \\
\text { atrioventricular conduction } \\
\text { blocks }\end{array}$ & $2.2 \%$ (within 72 h) (8) \\
\hline & $\begin{array}{l}\text { Supraventricular } \\
\text { tachycardia }\end{array}$ & 2.0\% (within 72 h) (8) \\
\hline & Unidentified & $\begin{array}{l}29.5 \% \text { (within } 48 \text { h) (44), } 25.0 \% \\
\text { (within } 72 \text { h) (8), 2.0\% (within } 4 \text { y) (45), } \\
31.0 \% \text { (46) }\end{array}$ \\
\hline & QT prolongation & $36.0 \%(24), 26.0 \%(25)$ \\
\hline & ST changes & $24.5 \%(24), 41.0 \%(25)$ \\
\hline & T wave inversion & $17.8 \%(24), 50.0 \%(25)$ \\
\hline & $\begin{array}{l}\text { Ischemia-like ECG } \\
\text { changes }\end{array}$ & $64.5 \%(25)$ \\
\hline \multirow{6}{*}{$\begin{array}{l}\text { Myocardial } \\
\text { damage }\end{array}$} & Myocardial injury & $88.0 \%(30)$ \\
\hline & cTnl elevate & $20.6 \%(35)$ \\
\hline & cTnT elevate & $9.6 \%(24), 10.9 \%(47)$ \\
\hline & hs-cTnT elevate & $54.4 \%(48)$ \\
\hline & CK-MB elevate & $34.4 \%(37)$ \\
\hline & Myocardial infarction & $3.5 \%(34), 4.9 \%(32)$ \\
\hline $\begin{array}{l}\text { Heart } \\
\text { failure }\end{array}$ & $\begin{array}{l}\text { Decompensated heart } \\
\text { failure }\end{array}$ & $17.0 \%(10)$ \\
\hline
\end{tabular}

provide the possibility to detect the exact pathophysiological mechanisms and related molecular pathways of CCS. The middle cerebral artery occlusion (MCAO) model is widely used for studying IS, which has been shown to cause different types of cardiac damages $(11,49-51)$. As revealed by experimental animal studies, the possible mechanisms of CCS include insular cortex injury, autonomic imbalance, catecholamine surge, systemic inflammation activation, and the myocardial ionic channel changed after IS (Table 2). All of the factors co-contributed to cardiomyocyte pathological damage, microcirculation disorders, and microvascular damage, resulting in arrhythmia, cardiac dysfunction, myocardial infarction, and myocardial fibrosis. Here we discuss the potential pathophysiological mechanisms of CCS (Figure 1).

\section{Autonomic Imbalance Induced by Insular Damage}

Insular cortex is important for the central autonomic neural network. Stimulation of the right insular cortex induces significant sympathetic response, while the left insular cortex stimulation enhances the parasympathetic tone (65). Insular cortical lesions commonly occur in the context of IS (66), causing autonomic imbalance and hence leading to cardiac arrhythmia and neurogenic cardiac damage. Up to $88 \%$ of patients with insular ischemic damage develop cardiac damage within weeks (22). Of note, cardiac dysfunction and arrhythmia are more severe in patients with right hemisphere insular cortex lesions when compared to those with left insular cortex lesions (1), which may be due to the incontrollable right insular cortex and therefore predisposing to rhythm instability. Cardiomyocyte damage after stroke is characterized by myofiber change to a granular staining pattern, mainly located in the cardiac nerves and the cardiac conduction system region $(6,31)$. This finding suggests that cardiac autonomic imbalance may damage cardiomyocytes directly. However, another study noted that autonomic dysfunction in patients within 6 months of IS mainly manifests as parasympathetic dysfunctions (67). In brief, autonomic imbalance induced by insular damage after stroke is an important pathogenesis for CCS. However, IS that is unrelated to the insula can also induce cardiac damage (68), suggesting that other pathogenic mechanisms are involved.

TABLE 2 | Cardiac damage in experimental animals after IS.

\begin{tabular}{|c|c|c|c|c|}
\hline Animal & Ischemic model & Ischemic area & Cardiac damage & Potential mechanism \\
\hline \multirow[t]{6}{*}{ Mice } & Middle cerebral artery & Right middle cerebral artery & Cardiac dysfunction, myocardial hypertrophy, & Inflammatory response (52) \\
\hline & occlusion (MCAO) & $(\mathrm{MCA})$ area & and fibrosis & Inflammasome activation (15) \\
\hline & & Left MCA area & Cardiac dysfunction & Catecholamines surge (53) \\
\hline & & Right/left MCA area & $\begin{array}{l}\text { Chronic cardiac systolic dysfunction and } \\
\text { myocardial fibrosis }\end{array}$ & Sympathetic overactivity (9) \\
\hline & Photothrombosis-induced & $\begin{array}{l}\text { Right MCA cortex without } \\
\text { insular cortex }\end{array}$ & $\begin{array}{l}\text { Cardiac dysfunction, myocardial fibrosis, and } \\
\text { hypertrophy }\end{array}$ & Inflammatory response (11) \\
\hline & & Frontal and parietal cortex & $\begin{array}{l}\text { Cardiac dysfunction, myocardial fibrosis, and } \\
\text { capillary rarefaction }\end{array}$ & $\begin{array}{l}\text { Inflammatory response and } \\
\text { oxidative stress (49) }\end{array}$ \\
\hline \multirow[t]{10}{*}{ Rat } & MCAO & Right MCA area & Heart rate variability change & Autonomic imbalance (50) \\
\hline & & & Cardiac dysfunction and myocardial damage & Oxidative stress (54) \\
\hline & & & Prolonged QT and arrhythmia & Ionic channel change (55) \\
\hline & & & Cardiac systolic and diastolic function & Ionic channel change (56) \\
\hline & & & MAP decline and myocardial damage & Catecholamines surge (57) \\
\hline & & & Cardiac myocytolysis & Catecholamines surge (58) \\
\hline & & Right/left MCA area & Myocardial damage and ECG abnormality & lonic channel change (59) \\
\hline & & & ECG changes and myocardial damage & Sympathetic overactivity (60) \\
\hline & $\begin{array}{l}\text { Polystyrene microsphere- } \\
\text { induced }\end{array}$ & Right/left hemisphere & $\begin{array}{l}\text { Cardiac dysfunction and increased cardiac } \\
\text { vulnerability }\end{array}$ & $\begin{array}{l}\text { Cardioprotective signaling pathway } \\
\text { injury (51) }\end{array}$ \\
\hline & Endothelin-1 induced & Right/left insular cortex & Endothelial dysfunction and myocardial fibrosis & Inflammatory response (61) \\
\hline Cat & MCAO & Left MCA area & Myocardial damage & Catecholamines surge (62) \\
\hline $\begin{array}{l}\text { Rhesus } \\
\text { macaque }\end{array}$ & Transient global ischemia & Global cerebral area & Myocardial apoptosis & Inflammatory response (63) \\
\hline In vitro & Oxygen-glucose deprivation & Primary neuronal cells & Reduction in myocardial viability & Cell death signal (64) \\
\hline
\end{tabular}




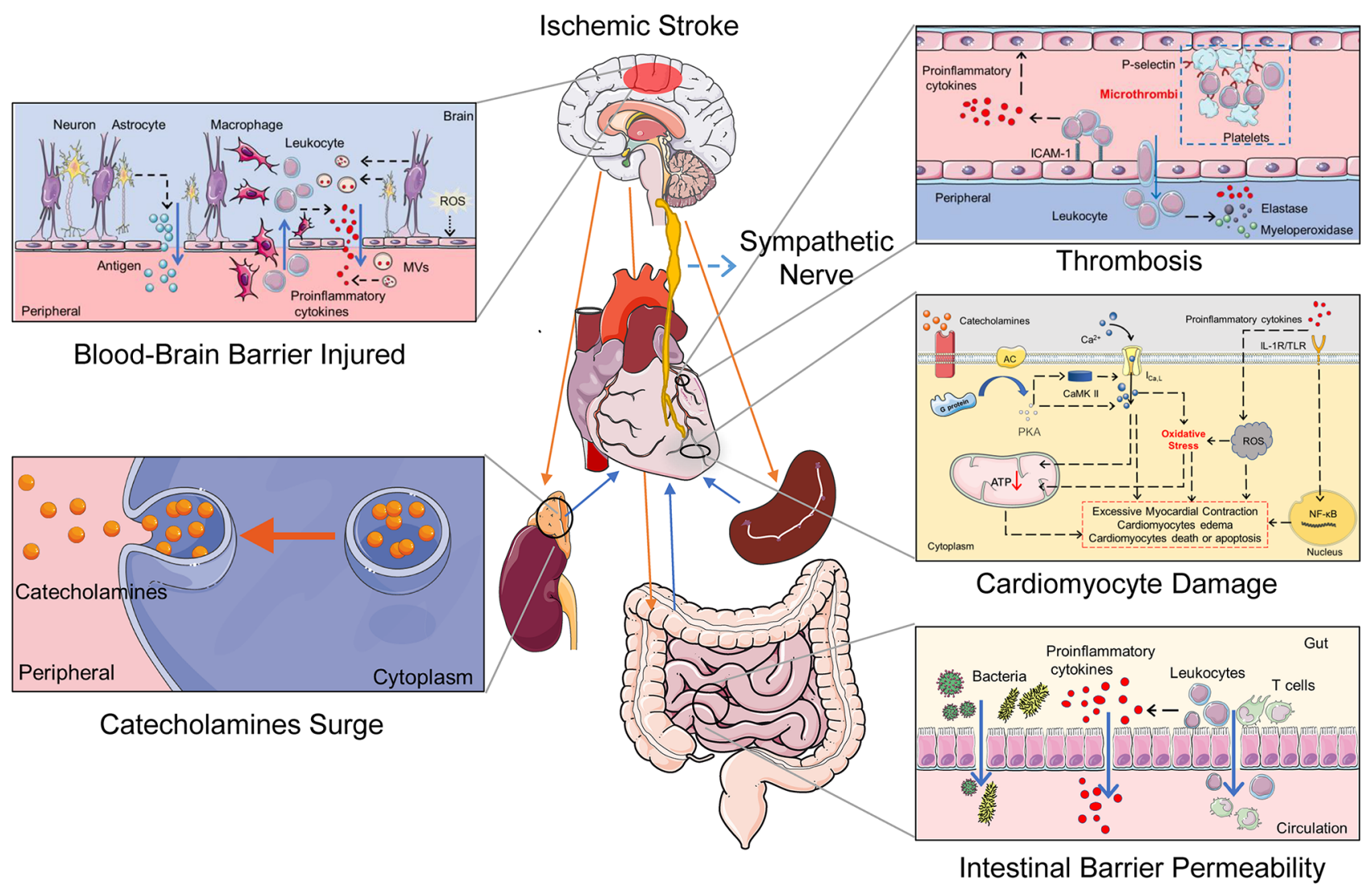

FIGURE 1 | The potential mechanisms of the cerebral-cardiac syndrome in ischemic stroke. Multiple organs and systems work together to mediate cardiac damage after IS. The HPA axis and sympathetic nerve activation after IS induce a catecholamine surge. Catecholamines activate the G protein-AC-cAMP-PKA cascade and increase cytosolic $\mathrm{Ca}^{2+}$ in the cardiomyocytes. Intracellular $\mathrm{Ca}^{2+}$ overload causes cardiomyocyte damage directly. Simultaneously, sympathetic nerve activation causes gut dysfunction and promotes the transfer of bacteria and proinflammatory cytokines. In addition, IS damages the BBB and neurons, which leaks the inflammatory activators to the peripheral. The spleen releases a variety of immune cells and participates in the activation of systemic inflammation after IS. Increased inflammatory cells and proinflammatory cytokines induce thrombosis and oxidative stress in cardiomyocytes, ultimately leading to cardiac damage. IL-1R, IL-1 receptor; TLR, Toll-like receptor; ROS, reactive oxygen species.

\section{Catecholamine Surge}

Catecholamine surge is the most common hypothesis for CCS. The hypothalamic-pituitary-adrenal (HPA) axis and sympathetic nerve activation are the main sources of catecholamines (69), which are activated after IS $(9,70)$. Increased catecholamines in the heart and circulation are closely related to the occurrence of arrhythmias and cardiomyocyte damage after IS (53, 57, 58, 60). Briefly, catecholamines activate $G$ protein-coupled receptors, which modulate the $G$ protein-adenyl cyclase (AC)-cyclic adenosine monophosphate (cAMP)-protein kinase A (PKA) cascade in cardiomyocytes (71). PKA can increase cytosolic calcium $\left(\mathrm{Ca}^{2+}\right)$ via activating $\mathrm{Ca}^{2+} /$ calmodulin-dependent protein kinase II (CaMK II) and phosphorylating L-type calcium channels (72). Intracellular $\mathrm{Ca}^{2+}$ overload not only provokes cardiac pathological changes such as cardiac myofibrillar degeneration and contraction band necrosis (71) but also causes mitochondrial dysfunction and decreased ATP synthesis, resulting in osmotic cell expansion and ultimately causing cardiomyocyte death or apoptosis (73). On the other hand, catecholamines activate $\beta_{3}$ adrenal receptors of adipocytes and induce fatty acids releasing into circulation. The free fatty acid accumulation in cardiomyocytes causes energy metabolic disturbance and promotes cardiac inflammation (69). Furthermore, catecholamines act on $\alpha_{1}$ receptors and then produce diacylglycerol and inositol triphosphate, causing coronary vasoconstriction. In addition, the oxidation product of catecholamines, aminochrome, also has cardiomyocyte and cardiovascular toxicity effects (vasoconstriction) (74). Overall, the activated HPA axis and sympathetic nerves induce catecholamine surge after IS and make great contribution to CCS.

\section{Immune Response and Systemic Inflammation}

The immune response and systemic inflammation after IS are known to exacerbate neurological impairment (75), which could be the responsible source for the subsequent CCS incidence. It has been reported that more than $50 \%$ of IS patients experience systemic inflammation within the initial 15 days (76) with a complex process involving immune cells and is driven by multifarious cytokines, proinflammatory chemokines, and sympathetic activity. The blood-brain barrier (BBB) is damaged after cerebral ischemia, followed by subsequent peripheral 
immune cell infiltration, which worsens BBB destruction afterward $(77,78)$. The infiltrated microglia and macrophages can release multiple proinflammatory cytokines into periphery circulation, such as IL-6 and IL-1 $\beta$ (79). Damaged neurons, astrocytes, and endothelial cells also produce peroxiredoxin family proteins, brain antigens, and microvesicles (2). These substances are generally confined to the cytoplasm or extracellular spaces in the brain and are released to the general circulation through the damaged $\mathrm{BBB}$ and cerebrospinal fluid drainage pathways, promoting immune response and systemic inflammation after IS (80). In the peripheral organs, spleen and gut are the major sources to regulate systemic inflammation after IS. It is undisputed that immune cells in the spleen are activated by IS (81). Meanwhile, sympathetic activation and catecholamine surge cause mesenteric vasoconstriction and intestinal paralysis, exacerbate intestinal ischemia, and increase gut-blood barrier disorder and proportional gut permeability, which promote intestinal bacterial and immune cell translocation from the gut to the peripheral organs (82). Furthermore, microbiome imbalance and the increased immune cells provoke severe systemic inflammation after IS (2).

Overactivation of the systemic inflammation causes cardiac pathological damage directly. As indicated, the activated immune response and systemic inflammation increase proinflammatory cytokines, which target the IL-1 receptor, the Toll-like receptor, or the transcription factor nuclear factorkappa B pathway to promote reactive oxygen species (ROS) production and to reduce the synthesis and bioavailability of nitric oxide (83). The inflammatory microenvironment also favors leukocyte activation and adhesion to the vasculature. Leukocyte-endothelial cell adhesion and platelet aggregation are mediating microthrombi and microvascular dysfunction, cardiomyocyte dysfunction, edema, and eventually cell death (84). Importantly, the increased monocytes and macrophages have been found in cardiac tissue after IS, which boost cardiac inflammation and hence promotes cardiac damage $(49,63)$. Inhibiting inflammatory responses have been proven as an effective way to attenuate cardiac damage in CCS $(11,49,52)$. All in all, increased inflammatory cytokines and immune cells after IS lead to cardiac pathological damage, which participates in the pathological process of CCS.

\section{DIABETIC STATUS EXACERBATES CEREBRAL-CARDIAC SYNDROME}

\section{Clinical Evidence}

Diabetes increases the incidence of cardiac complications after IS, which manifest as myocardial infarction, congestive heart failure (85), arrhythmia, cardiac arrest (16), and exacerbate mortality and worse neural prognosis in the post-stroke state $(15,49,86)$. Burkot et al. have reported that heart failure occurrence rate after IS is $22.3 \%$ in diabetic patients and $15.1 \%$ without diabetes (10). The level of myocardial enzyme from damaged myocardium are higher in diabetic IS patients, such as cTnI and hs-cTnT, which have strongly associated with atrial fibrillation (48). Furthermore, compared to the non-diabetic patients, the incidence of myocardial infarction was 3.5 times higher in diabetic patients in the post-stroke state (87). A recent study showed that canagliflozin (an anti-hyperglycemic drug treats diabetes) can significantly reduce the incidence of myocardial infarction and cardiovascular death after stroke (85). Another case report has also suggested that insulin therapy is beneficial for stroke patients with complicated diabetes who suffered from neurogenic stunned myocardium (88). Together, these studies suggest that a potential connection may exist between diabetes and CCS.

\section{Potential Pathogenesis}

The severity, duration, and clinical manifestation of diabetes should be considered when facilitating the CCS, and there are a few literatures that focus on it. The exact mechanisms contributing to CCS in the context of diabetes are obscure. However, available evidences are emerging (15, 49). Firstly, diabetes increased the vulnerability and susceptibility of both the brain and the heart in the pre-stroke stage. Secondly, diabetes is known to induce systemic inflammation and to trigger oxidative and hyperosmolar stress, which lead to more severe cardiac inflammatory damage in the diabetic stroke status. Herein we characterize the potential pathogenesis to show how diabetes affects CCS (Figure 2).

\section{Autonomic Neuropathy in Diabetes}

The autonomic imbalance is an important mechanism of CCS. Diabetic stroke leads to larger ischemic infarcts and more severe neurological deficits. Severe cerebral damage may be the basis for exacerbating CCS $(19,89)$. Diabetic autonomic neuropathy is common in diabetic patients, and cardiac autonomic neuropathy (CAN) is one of the common subtypes (90). CAN is characterized by parasympathetic denervation and augmented sympathetic tone (91). A stronger sympathetic tone can cause severe cardiac damage after the IS onset (9).

\section{Boosted Catecholamine Surge and $\beta$-Adrenergic Receptors Disorder in Diabetes}

Diabetes provokes cardiac sympathetic nerve excitation, metabolic disorder, and subsequent catecholamine surge (92). Catecholamine surge can induce cardiac pathological damage directly (93). In addition, catecholamine surge acts on adipose tissue and hence increases free fatty acids after IS. Myocardial insulin resistance leads to a reduction in regional glucose utilization, and the myocardial energy supply balance is shifted to free fatty acid metabolism in the context of diabetes (94). Hence, the demand for free fatty acids in the myocardium may increase in diabetic IS. However, excessive free fatty acids can induce cardiomyocyte damage, myocardial fibrosis, and cardiac remodeling via increasing myocardial oxygen consumption, ROS production, and myocardial mitochondrial dysfunction (95). The cardiac $\beta$-adrenergic receptors ( $\beta$-ARs) are the main receptors of catecholamine. Diabetic status alters the expression and responsiveness of $\beta$-AR of the myocardium, manifesting as $\beta_{1}$-AR and $\beta_{2}$-AR decreased while $\beta_{3}$-AR increased (96). It is believed that $\beta_{2}$-AR activation provides cardioprotection. 


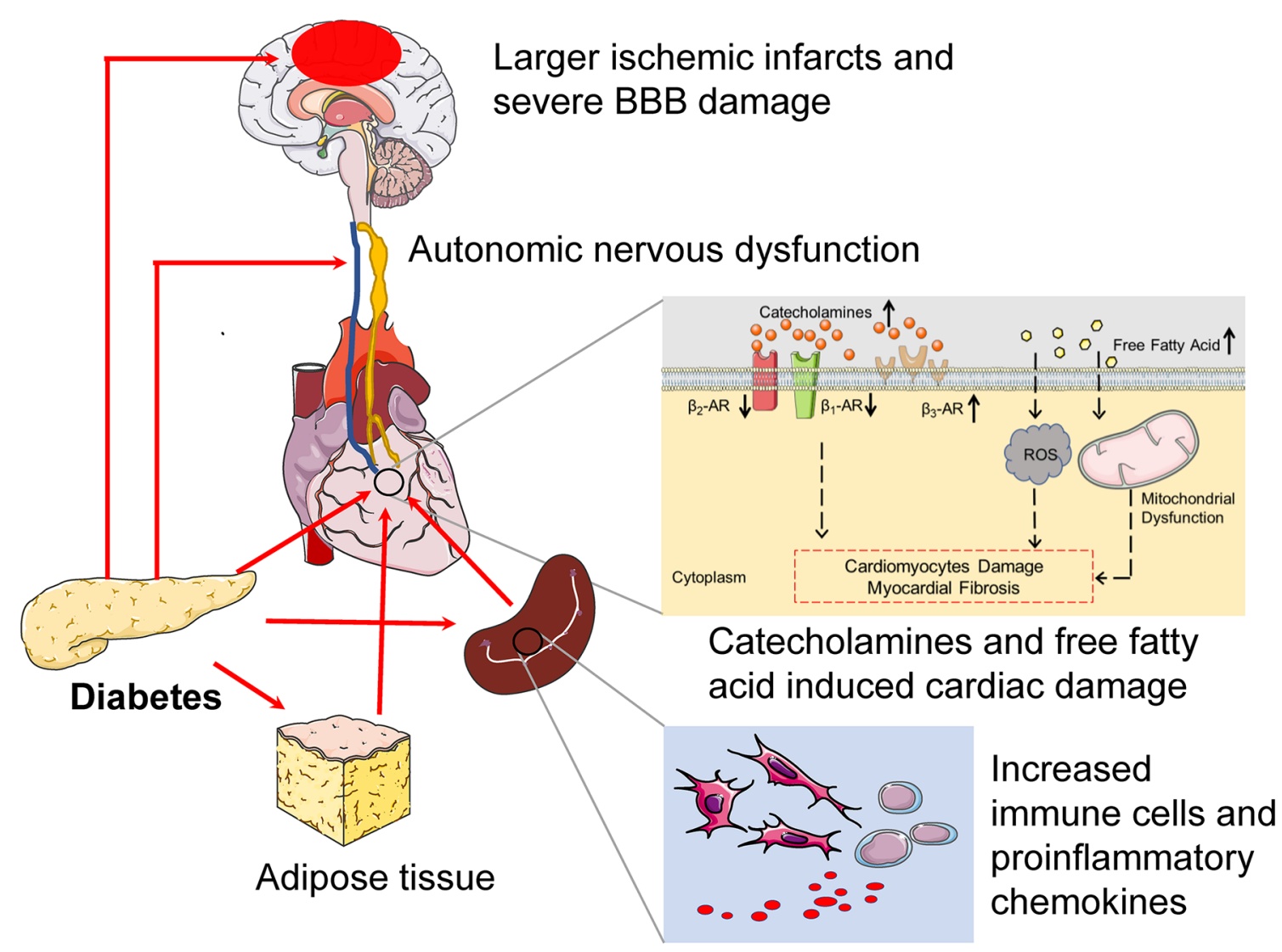

FIGURE 2 | The potential pathogenesis of diabetes exacerbates cerebral-cardiac syndrome. In pre-stroke states, diabetes induces preexisting injury both of the brain and the heart. CAN is a common complication in diabetes, which is characterized by parasympathetic denervation and overactivated sympathetic tone. Furthermore, the expression of $\beta_{1}$-AR and $\beta_{2}$-AR decreased, while the $\beta 3$-AR increased in the diabetic heart. Diabetes also provides a low-grade systemic inflammatory environment, which manifests as increased immune cells and proinflammatory cytokine levels. All of these provide a suitable condition for CCS. In the context of diabetes, the larger ischemic infract and severe BBB damage can be detected during the IS onset, which provoke severe systemic inflammation and cause severe cardiac inflammatory damage. Catecholamines surge also increase after IS in diabetes. Catecholamines surge not only damage cardiomyocyte directly but also act on adipose tissue, which increases free fatty acids. The boosted free fatty acids induce ROS production and mitochondrial dysfunction, which promote cardiac damage. Above all, diabetes induces preexisting cardiac damage and increases heart vulnerability, and cultivates a "primed" inflammatory microenvironment before IS and severe systemic inflammation and catecholamines surge after IS, hence exacerbating CCS. CAN, cardiac autonomic neuropathy.

However, $\beta_{2}$-AR displayed a reduced reactivity of adrenergic stimulation in the diabetic heart, which caused the exercise capability damage and impaired cardiac contractile in mice (97). Together, the superimposed catecholamine surge combined with the $\beta$-ARs disorder may be responsible for severe CCS in diabetes.

\section{Diabetes Exacerbates Cardiac Inflammatory Damage}

As immune response and systemic inflammation are important triggers for CCS, it is rational that other risk factors that share semblable inflammatory mechanism also potentiate the progression of CCS. Diabetes indicates a preexisting chronic low-grade systemic inflammatory disease that manifests as elevated serum leukocyte counts and C-reactive protein, adiponectin, and proinflammatory cytokine levels (98). Furthermore, diabetic patients suffer from severe systemic inflammation after IS, manifesting as increased activation of circulating neutrophils and monocytes (99). In diabetes, macrophage mobilization and infiltration have been observed in the heart even in the absence of stroke (100), and macrophage infiltration is more obvious after IS (15). Increased macrophages and neutrophils form an inflammatory activation loop and cause severe inflammatory damage (101). Diabetes affects BBB integrity and permeability, which may increase the leakage of multiple inflammatory factors from the brain after stroke (102). These findings strengthen the hypothesis that diabetes establishes a "primed" suitable environment before IS and drives severe systemic inflammation after IS, which may exacerbate cardiac inflammatory damage and induce CCS. Anti-inflammatory therapy via reducing the inflammation and macrophage infiltration in the heart after IS may be a potential treatment for diabetic CCS $(15,49)$. Therefore, excessive systemic inflammation is an indispensable pathogenesis in severe CCS in the context of diabetes. 


\section{NLRP3 INFLAMMASOME IN DIABETIC CEREBRAL-CARDIAC SYNDROME}

Inflammation is no doubt a direction that needed further exploration in CCS, particularly for diabetes state. Recently, the NLRP3 inflammasome has been broadly studied of its close relationship with inflammation diseases (103). Importantly, NLRP3 inflammasome activation plays an indispensable role in diabetes and diabetic complications $(104,105)$. However, it is unclear whether diabetic CCS relies on NLRP3 inflammasome activation. How does NLRP3 inflammasome participate in the onset of diabetic CCS? Which cell types in the heart response to the activated NLRP3 inflammasome after IS and how does it lead to cardiac damage? The following sections will focus on the recent findings that refer to the above questions.

\section{NLRP3 Inflammasome Activation Induced Cardiac Damage in Diabetic Cerebral- Cardiac Syndrome}

NLRP3 is highly expressed and activated in immune cells (103). The NLRP3 inflammasome contains NLRP3, the apoptosisassociated speck-like protein containing and the effector cysteine protease caspase-1 (105). Various danger signals activate the NLRP3 inflammasome by pathogen- and damageassociated molecular patterns, such as high glycemic environments and bacterial and viral nucleic acids (13). The activated NLRP3 inflammasome further promotes the maturation and release of IL-1 $\beta$ and IL-18, as extensively described in a recent review (13).

Of note, NLRP3 inflammasome activation is an important pathogenic mechanism of diabetes and diabetic complications $(104,105)$. NLRP3 inflammasome activation induces insulin resistance and impairs pancreatic $\beta$-cells, participating in the development of diabetes (14). NLRP3 inflammasome-IL-1 $\beta$ secretion in cardiac macrophage induces a decrease in potassium current and an increase in calcium sparks in cardiomyocytes, promoting the development of diabetesinduced arrhythmia (106). Our previous study has suggested that NLRP3 inflammasome activation increased in the myocardium after IS in a diabetic mouse model (15), indicating that the NLRP3 inflammasome may play an important role in diabetic CCS. NLRP3 inflammasome can be activated in the heart after IS. Firstly, proinflammatory cytokines, microvesicles, and antigens are leaked from the ischemic brain (2). Bacteria, immune cells, and other toxic substances such as the microbial metabolite trimethylamine translocate after ISinduced gut-blood barrier disorder (2), which can impact the myocardium and activate the cardiac NLRP3 inflammasome. Secondly, catecholamine surges causes intracellular CaMK II activation, $\mathrm{Ca}^{2+}$ overload, and ROS production, which are directly or indirectly involved in the activation of NLRP3 inflammasome (107). Also, IS-induced mitochondrial dysfunction in cardiomyocytes causes the loss of mitochondrial membrane potential and release of mitochondrial DNA into the cytosol, which further activates NLRP3 inflammasome (54). Furthermore, hyperglycemia can also activate NLRP3 inflammasome in the myocardium (108). Overall, the cardiac NLRP3 inflammasome may be more sensitive to be activated in diabetic CCS. Sequentially, the activated NLRP3 inflammasome exacerbates cardiac inflammatory damage via mediating the maturation of IL-1 $\beta$ and IL-18 (109).

A previous study has suggested that NLRP3 inflammasome is mainly activated in cardiac monocyte-derived macrophages under the pathological state (110). However, NLRP3 inflammasome is expressed in various cardiac cell types including cardiomyocytes, fibroblasts, microvascular endothelial cells, and cardiac macrophages (109). NLRP3 inflammasome activation in different cardiac cells may play a different role in diabetic CCS. NLRP3 inflammasome activation in cardiomyocytes promotes abnormal sarcoplasmic reticulum $\mathrm{Ca}^{2+}$ release, causing ectopic firing and augmented $\mathrm{K}^{+}$currents that abbreviate electrical remodeling and promote the development of atrial fibrillation (111). In myocardial fibroblasts, NLRP3 inflammasome activation regulates mitochondrial ROS production, which eventually leads to the expression of profibrotic genes (such as collagen one and $\alpha$ smooth muscle actin) and then provokes myocardial fibrosis and cardiac remodeling (112). NLRP3 inflammasome activation also enhances macrophage recruitment, which is involved in the progression of cardiac inflammation and the formation of plaques and destabilizes the plaque, which increased the incidence of myocardial infarction $(113,114)$. However, NLRP3 inflammasome activation not only increases the number of macrophages but also affects the macrophage polarization state. Generally, macrophage polarization can be divided into the proinflammatory M1 type and the anti-inflammatory M2 type. M1 macrophages promote cardiac inflammation, cardiac fibrosis, and cardiac dysfunction, while M2 macrophages reduce cardiac inflammation and remodeling (115). NLRP3 inflammasome activation provokes macrophage to M1 type and hence exacerbates cardiac inflammatory injury (116). Inhibiting the NLRP3 inflammasome activation can promote macrophage to M2 polarization, which attenuates post-infarct cardiac dysfunction (117).

In summary, diabetic stroke induces NLRP3 inflammasome activation via various mechanisms in cardiac macrophages, microvascular endothelial cells, cardiomyocytes, and cardiac fibroblasts, which increase cardiac inflammation, recruit macrophage infiltration, and induce macrophage polarization. Excessive inflammation ultimately leads to cardiomyocyte necrosis, contraction band necrosis, plaque rupture, endothelial dysfunction, and the activation of myofibroblast $(3,118,119)$, resulting in arrhythmia, myocardial fibrosis, myocardial infarction, and heart failure (Figure 3).

\section{CONCLUSIONS AND FUTURE DIRECTION}

Conclusively, we summarize the features and the responsible mechanisms of CCS in the review. CCS refers to the cardiac damage after IS that has various clinical manifestations, including arrhythmia, myocardial damage, and heart failure. Cardiac complications predict the development and prognosis 


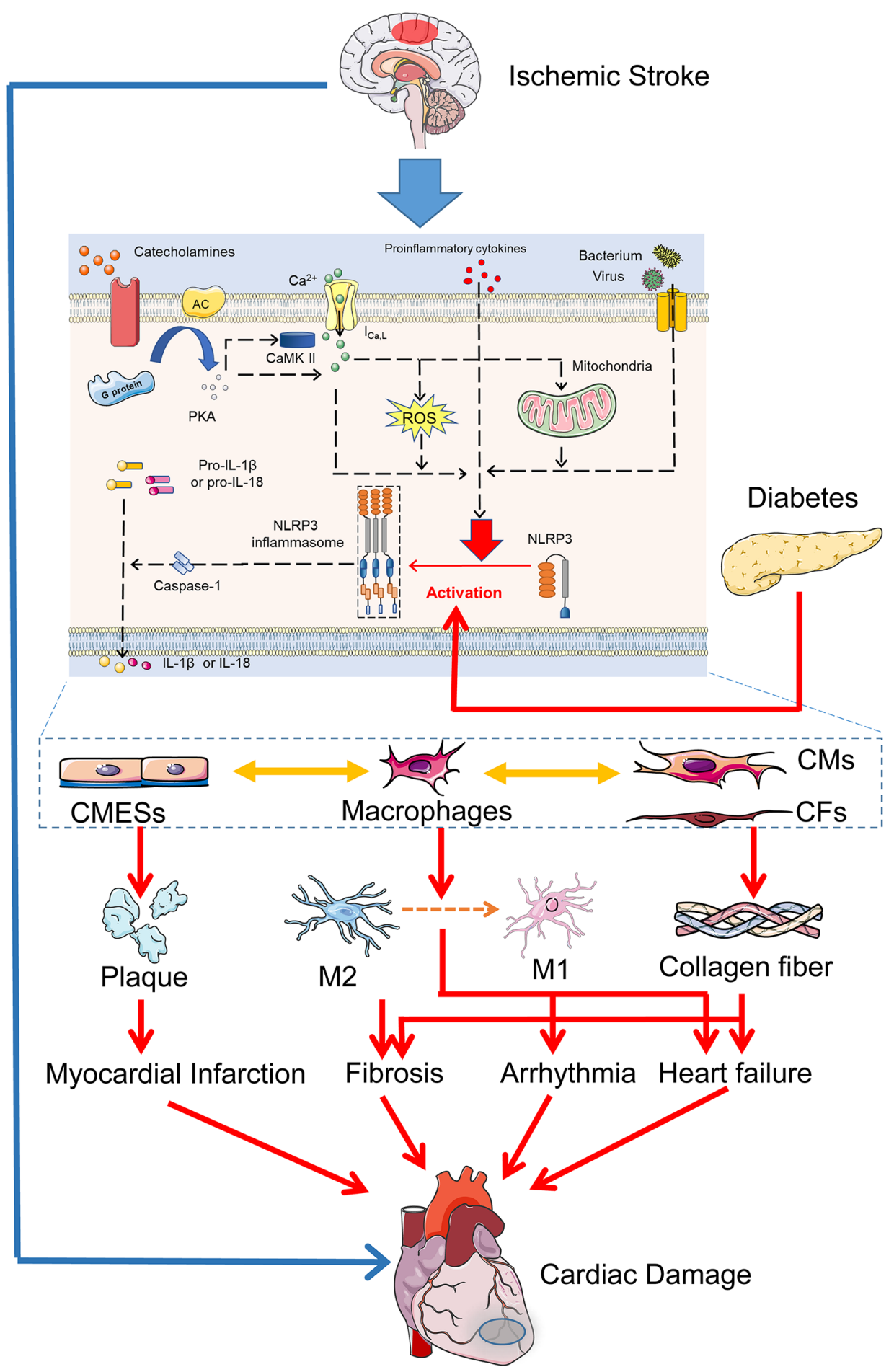

FIGURE 3 | NLRP3 inflammasome activation in diabetic cerebral-cardiac syndrome. Increased catecholamines, proinflammatory cytokines, and bacteria after IS induce intracellular $\mathrm{Ca}^{2+}$ overload, mitochondrial dysfunction, ROS production, and activation of CaMKIl in cardiac cells. These activators and hyperglycemia in diabetes directly activate the NLRP3 inflammasome in various cardiac cell types. NLRP3 inflammasome activation in CMESs induces platelet and macrophage aggregation. In cardiac macrophages, NLRP3 inflammasome activation promotes M1 macrophage polarization and provokes the cardiac inflammation damage. In CMs and CFs, NLRP3 inflammasome activation increases the expression of profibrotic genes and promotes myocardial fibrosis. Overall, IS and diabetes coactivate NLRP3 inflammasome in various cardiac cells, which ultimately leads to arrhythmia, myocardial fibrosis, myocardial infarction, and heart failure, resulting in diverse cardiac damage. CMESs, cardiac microvascular endothelial cells; CMs, cardiomyocytes; CFs, cardiac fibroblasts. 
of IS in turn. In addition, we summarize the responsible mechanisms in CCS, which include insular cortex injury, autonomic imbalance, catecholamine surge, immune responses, and systemic inflammation after IS. Furthermore, we try to indicate the role of diabetes in CCS and the link of NLRP3 inflammasome between diabetes and CCS. Of note, diabetes is a risk factor in CCS (15). On one hand, diabetes induces preexisting injury in the heart before CCS onset. The preexisting injury increases the vulnerability and susceptibility of cardiac damage after IS and provides a suitable environment for CCS. On the other hand, boosted catecholamine surge and severe inflammatory response provoke cardiac pathological changes and aggravate CCS after the IS onset in diabetes. As the key element of inflammation, NLRP3 inflammasome plays an essential role in inflammation diseases (103). Therefore, we further focus on the role of NLRP3 inflammasome in diabetic CSS. We characterize the ways of NLRP3 inflammasome activation and the subsequent cardiac pathological damage in CCS combined with diabetes and propose that NLRP3 inflammasome-mediated inflammation may be a potential target in diabetic CCS. However, the other pathogenesis of diabetic CCS is also worthy of further investigation. Overall,

\section{REFERENCES}

1. Scheitz JF, Nolte CH, Doehner W, Hachinski V, Endres M. Stroke-Heart Syndrome: Clinical Presentation and Underlying Mechanisms. Lancet Neurol (2018) 17(12):1109-20. doi: 10.1016/S1474-4422(18)30336-3

2. Chen Z, Venkat P, Seyfried D, Chopp M, Yan T, Chen J. Brain-Heart Interaction: Cardiac Complications After Stroke. Circ Res (2017) 121 (4):451-68. doi: 10.1161/CIRCRESAHA.117.311170

3. Sposato LA, Hilz MJ, Aspberg S, Murthy SB, Bahit MC, Hsieh CY, et al. Post-Stroke Cardiovascular Complications and Neurogenic Cardiac Injury: JACC State-of-the-Art Review. J Am Coll Cardiol (2020) 76(23):2768-85. doi: 10.1016/j.jacc.2020.10.009

4. Zhao Q, Yan T, Li L, Chopp M, Venkat P, Qian Y, et al. Immune Response Mediates Cardiac Dysfunction After Traumatic Brain Injury. J Neurotrauma (2019) 36(4):619-29. doi: 10.1089/neu.2018.5766

5. Amin HZ, Amin LZ, Pradipta A. Takotsubo Cardiomyopathy: A Brief Review. J Med Life (2020) 13(1):3-7. doi: 10.25122/jml-2018-0067

6. Samuels MA. The Brain-Heart Connection. Circulation (2007) 116(1):7784. doi: 10.1161/CIRCULATIONAHA.106.678995

7. Kumar S, Selim MH, Caplan LR. Medical Complications After Stroke. Lancet Neurol (2010) 9(1):105-18. doi: 10.1016/S1474-4422(09)70266-2

8. Kallmunzer B, Breuer L, Kahl N, Bobinger T, Raaz-Schrauder D, Huttner $\mathrm{HB}$, et al. Serious Cardiac Arrhythmias After Stroke: Incidence, Time Course, and Predictors-A Systematic, Prospective Analysis. Stroke (2012) 43(11):2892-7. doi: 10.1161/STROKEAHA.112.664318

9. Bieber M, Werner RA, Tanai E, Hofmann U, Higuchi T, Schuh K, et al. Stroke-Induced Chronic Systolic Dysfunction Driven by Sympathetic Overactivity. Ann Neurol (2017) 82(5):729-43. doi: 10.1002/ana.25073

10. Burkot J, Kopec G, Pera J, Slowik A, Dziedzic T. Decompensated Heart Failure Is a Strong Independent Predictor of Functional Outcome After Ischemic Stroke. J Card Fail (2015) 21(8):642-6. doi: 10.1016/ j.cardfail.2015.03.008

11. Yan T, Chen Z, Chopp M, Venkat P, Zacharek A, Li W, et al. Inflammatory Responses Mediate Brain-Heart Interaction After Ischemic Stroke in Adult Mice. J Cereb Blood Flow Metab (2020) 40(6):1213-29. doi: 10.1177/ $0271678 X 18813317$

12. Poznyak A, Grechko AV, Poggio P, Myasoedova VA, Alfieri V, Orekhov AN. The Diabetes Mellitus-Atherosclerosis Connection: The Role of Lipid and it is important to strengthen post-stroke cardiac monitoring in the clinic, especially in diabetic patients, which may reduce the mortality associated with IS.

\section{AUTHOR CONTRIBUTIONS}

H-FZ, F-XL, H-BL, W-BL, Z-JY, and S-YX contributed to the review including the designing and planning. $\mathrm{H}-\mathrm{BL}, \mathrm{F}-\mathrm{XL}$, and J$\mathrm{YZ}$ wrote the manuscript. W-BL and H-FZ contributed to critically revising the work. All authors read and approved the final manuscript.

\section{FUNDING}

This work was supported by grant 81771232,82070526 (to HFZ) and 81974192 (to F-XL) from the National Natural Science Foundation of China and grant 2019A1515010654, 2021A1515011652 (to H-FZ) from the Natural Science Foundation of Guangdong Province, China.

Glucose Metabolism and Chronic Inflammation. Int J Mol Sci (2020) 21 (5):1835. doi: 10.3390/ijms21051835

13. Swanson KV, Deng M, Ting JP. The NLRP3 Inflammasome: Molecular Activation and Regulation to Therapeutics. Nat Rev Immunol (2019) 19 (8):477-89. doi: 10.1038/s41577-019-0165-0

14. Iannantuoni F, Diaz-Morales N, Escribano-Lopez I, Sola E, Roldan-Torres I, Apostolova N, et al. Does Glycemic Control Modulate the Impairment of NLRP3 Inflammasome Activation in Type 2 Diabetes? Antioxid Redox Signal (2019) 30(2):232-40. doi: 10.1089/ars.2018.7582

15. Lin HB, Wei GS, Li FX, Guo WJ, Hong P, Weng YQ, et al. MacrophageNLRP3 Inflammasome Activation Exacerbates Cardiac Dysfunction After Ischemic Stroke in a Mouse Model of Diabetes. Neurosci Bull (2020) 36 (9):1035-45. doi: 10.1007/s12264-020-00544-0

16. Prosser J, MacGregor L, Lees KR, Diener HC, Hacke W, Davis S, et al. Predictors of Early Cardiac Morbidity and Mortality After Ischemic Stroke. Stroke (2007) 38(8):2295-302. doi: 10.1161/STROKEAHA.106.471813

17. Soros P, Hachinski V. Cardiovascular and Neurological Causes of Sudden Death After Ischaemic Stroke. Lancet Neurol (2012) 11(2):179-88. doi: 10.1016/S1474-4422(11)70291-5

18. Ozdemir O, Hachinski V. Brain Lateralization and Sudden Death: Its Role in the Neurogenic Heart Syndrome. J Neurol Sci (2008) 268(1-2):6-11. doi: 10.1016/j.jns.2007.11.009

19. Yoshimura S, Toyoda K, Ohara T, Nagasawa H, Ohtani N, Kuwashiro T, et al. Takotsubo Cardiomyopathy in Acute Ischemic Stroke. Ann Neurol (2008) 64(5):547-54. doi: 10.1002/ana.21459

20. Ruthirago D, Julayanont P, Tantrachoti P, Kim J, Nugent K. Cardiac Arrhythmias and Abnormal Electrocardiograms After Acute Stroke. Am J Med Sci (2016) 351(1):112-8. doi: 10.1016/j.amjms.2015.10.020

21. Seifert F, Kallmunzer B, Gutjahr I, Breuer L, Winder K, Kaschka I, et al. Neuroanatomical Correlates of Severe Cardiac Arrhythmias in Acute Ischemic Stroke. J Neurol (2015) 262(5):1182-90. doi: 10.1007/s00415015-7684-9

22. Fernandez V, Bejot Y, Zeller M, Hamblin J, Daubail B, Jacquin A, et al. Silent Atrial Fibrillation After Ischemic Stroke or Transient Ischemic Attack: Interest of Continuous ECG Monitoring. Eur Neurol (2014) 71(5-6):3138. doi: 10.1159/000357561

23. Rizos T, Horstmann S, Dittgen F, Tager T, Jenetzky E, Heuschmann P, et al. Preexisting Heart Disease Underlies Newly Diagnosed Atrial Fibrillation 
After Acute Ischemic Stroke. Stroke (2016) 47(2):336-41. doi: 10.1161/ STROKEAHA.115.011465

24. Fure B, Bruun Wyller T, Thommessen B. Electrocardiographic and Troponin T Changes in Acute Ischaemic Stroke. J Intern Med (2006) 259 (6):592-7. doi: 10.1111/j.1365-2796.2006.01639.x

25. Dogan A, Tunc E, Ozturk M, Kerman M, Akhan G. Electrocardiographic Changes in Patients With Ischaemic Stroke and Their Prognostic Importance. Int J Clin Pract (2004) 58(5):436-40. doi: 10.1111/j.13685031.2004.00010.x

26. Tatschl C, Stollberger C, Matz K, Yilmaz N, Eckhardt R, Nowotny M, et al. Insular Involvement Is Associated With QT Prolongation: ECG Abnormalities in Patients With Acute Stroke. Cerebrovasc Dis (2006) 21 (1-2):47-53. doi: 10.1159/000089594

27. Wong KY, Mac Walter RS, Douglas D, Fraser HW, Ogston SA, Struthers AD. Long QTc Predicts Future Cardiac Death in Stroke Survivors. Heart (2003) 89(4):377-81. doi: 10.1136/heart.89.4.377

28. Scheitz JF, Erdur H, Haeusler KG, Audebert HJ, Roser M, Laufs U, et al. Insular Cortex Lesions, Cardiac Troponin, and Detection of Previously Unknown Atrial Fibrillation in Acute Ischemic Stroke: Insights From the Troponin Elevation in Acute Ischemic Stroke Study. Stroke (2015) 46 (5):1196-201. doi: 10.1161/STROKEAHA.115.008681

29. Edwards JD, Kapral MK, Fang J, Saposnik G, Gladstone DJInvestigators of the Registry of the Canadian Stroke N. Underutilization of Ambulatory ECG Monitoring After Stroke and Transient Ischemic Attack: Missed Opportunities for Atrial Fibrillation Detection. Stroke (2016) 47(8):19829. doi: 10.1161/STROKEAHA.115.012195

30. Ay H, Koroshetz WJ, Benner T, Vangel MG, Melinosky C, Arsava EM, et al. Neuroanatomic Correlates of Stroke-Related Myocardial Injury. Neurology (2006) 66(9):1325-9. doi: 10.1212/01.wnl.0000206077.13705.6d

31. Kolin A, Norris JW. Myocardial Damage From Acute Cerebral Lesions. Stroke (1984) 15(6):990-3. doi: 10.1161/01.str.15.6.990

32. Mathias TL, Albright KC, Boehme AK, Monlezun D, George AJ, Jones E, et al. The Impact of Myocardial Infarction vs. Pneumonia on Outcome in Acute Ischemic Stroke. J Cardiovasc Dis (2014) 2(1):1-3.

33. Touze E, Varenne O, Chatellier G, Peyrard S, Rothwell PM, Mas JL. Risk of Myocardial Infarction and Vascular Death After Transient Ischemic Attack and Ischemic Stroke: A Systematic Review and Meta-Analysis. Stroke (2005) 36(12):2748-55. doi: 10.1161/01.STR.0000190118.02275.33

34. Boulanger M, Li L, Lyons S, Lovett NG, Kubiak MM, Silver L, et al. Essen Risk Score in Prediction of Myocardial Infarction After Transient Ischemic Attack or Ischemic Stroke Without Prior Coronary Artery Disease. Stroke (2019) 50(12):3393-9. doi: 10.1161/STROKEAHA.119.025831

35. VanHouten J, Fricker G, Collins B, Bhatia R, Ellis C, Schrag M. Circulating Troponin I Level in Patients With Acute Ischemic Stroke. Curr Neurol Neurosci Rep (2018) 18(6):32. doi: 10.1007/s11910-018-0842-6

36. He L, Wang J, Dong W. The Clinical Prognostic Significance of Hs-Ctnt Elevation in Patients With Acute Ischemic Stroke. BMC Neurol (2018) 18 (1):118. doi: 10.1186/s12883-018-1121-5

37. Ay H, Arsava EM, Saribas O. Creatine Kinase-MB Elevation After Stroke Is Not Cardiac in Origin: Comparison With Troponin T Levels. Stroke (2002) 33(1):286-9. doi: 10.1161/hs0102.101544

38. Furtner M, Ploner T, Hammerer-Lercher A, Pechlaner R, Mair J. The HighSensitivity Cardiac Troponin T Assay Is Superior to Its Previous Assay Generation for Prediction of 90-Day Clinical Outcome in Ischemic Stroke. Clin Chem Lab Med (2012) 50(11):2027-9. doi: 10.1515/cclm-2012-0176

39. Li Y, Fitzgibbons TP, McManus DD, Goddeau RP Jr, Silver B, Henninger N. Left Ventricular Ejection Fraction and Clinically Defined Heart Failure to Predict 90Day Functional Outcome After Ischemic Stroke. J Stroke Cerebrovasc Dis (2019) 28(2):371-80. doi: 10.1016/j.jstrokecerebrovasdis.2018.10.002

40. Murthy SB, Shah S, Venkatasubba Rao CP, Suarez JI, Bershad EM. Clinical Characteristics of Myocardial Stunning in Acute Stroke. J Clin Neurosci (2014) 21(8):1279-82. doi: 10.1016/j.jocn.2013.11.022

41. Jung JM, Kim JG, Kim JB, Cho KH, Yu S, Oh K, et al. Takotsubo-Like Myocardial Dysfunction in Ischemic Stroke: A Hospital-Based Registry and Systematic Literature Review. Stroke (2016) 47(11):2729-36. doi: 10.1161/ STROKEAHA.116.014304

42. Micheli S, Agnelli G, Caso V, Alberti A, Palmerini F, Venti M, et al. Acute Myocardial Infarction and Heart Failure in Acute Stroke Patients: Frequency and Influence on Clinical Outcome. J Neurol (2012) 259(1):106-10. doi: 10.1007/s00415-011-6136-4

43. Kozdag G, Yaymaci M, Iseri P, Ertas G, Emre E, Bildirici U, et al. Ischemic Stroke History Predicts Increased Cardiovascular Mortality in Chronic Heart Failure. Anadolu Kardiyol Derg (2011) 11(5):421-7. doi: 10.5152/ akd.2011.109

44. Fernandez-Menendez S, Garcia-Santiago R, Vega-Primo A, Gonzalez Nafria N, Lara-Lezama LB, Redondo-Robles L, et al. Cardiac Arrhythmias in Stroke Unit Patients. Evaluation of the Cardiac Monitoring Data. Neurologia (2016) 31(5):289-95. doi: 10.1016/j.nrl.2015.03.013

45. Dahlin AA, Parsons CC, Barengo NC, Ruiz JG, Ward-Peterson M, Zevallos JC. Association of Ventricular Arrhythmia and In-Hospital Mortality in Stroke Patients in Florida: A Nonconcurrent Prospective Study. Medicine (2017) 96(28):e7403. doi: 10.1097/MD.0000000000007403

46. Lavy S, Yaar I, Melamed E, Stern S. The Effect of Acute Stroke on Cardiac Functions as Observed in an Intensive Stroke Care Unit. Stroke (1974) 5 (6):775-80. doi: 10.1161/01.str.5.6.775

47. Cojocaru IM, Cojocaru M, Sapira V, Trasca D, Serban AS, Tacu N, et al. Troponin T Changes in Acute Ischemic Stroke. Rom J Intern Med (2014) 52 (2):97-101.

48. Faiz KW, Thommessen B, Einvik G, Brekke PH, Omland T, Ronning OM. Determinants of High Sensitivity Cardiac Troponin T Elevation in Acute Ischemic Stroke. BMC Neurol (2014) 14:96. doi: 10.1186/1471-2377-14-96

49. Venkat P, Cui C, Chen Z, Chopp M, Zacharek A, Landschoot-Ward J, et al. CD133+Exosome Treatment Improves Cardiac Function After Stroke in Type 2 Diabetic Mice. Transl Stroke Res (2021) 12(1):112-24. doi: 10.1007/ s12975-020-00807-y

50. Kodama T, Kamata K, Fujiwara K, Kano M, Yamakawa T, Yuki I, et al. Ischemic Stroke Detection by Analyzing Heart Rate Variability in Rat Middle Cerebral Artery Occlusion Model. IEEE Trans Neural Syst Rehabil Eng (2018) 26(6):1152-60. doi: 10.1109/TNSRE.2018.2834554

51. Meloux A, Rigal E, Rochette L, Cottin Y, Bejot Y, Vergely C. Ischemic Stroke Increases Heart Vulnerability to Ischemia-Reperfusion and Alters Myocardial Cardioprotective Pathways. Stroke (2018) 49(11):2752-60. doi: 10.1161/STROKEAHA.118.022207

52. Chen J, Cui C, Yang X, Xu J, Venkat P, Zacharek A, et al. MiR-126 Affects Brain-Heart Interaction After Cerebral Ischemic Stroke. Transl Stroke Res (2017) 8(4):374-85. doi: 10.1007/s12975-017-0520-z

53. Min J, Farooq MU, Greenberg E, Aloka F, Bhatt A, Kassab M, et al. Cardiac Dysfunction After Left Permanent Cerebral Focal Ischemia: The Brain and Heart Connection. Stroke (2009) 40(7):2560-3. doi: 10.1161/ STROKEAHA.108.536086

54. Wang R, Liu YY, Liu XY, Jia SW, Zhao J, Cui D, et al. Resveratrol Protects Neurons and the Myocardium by Reducing Oxidative Stress and Ameliorating Mitochondria Damage in a Cerebral Ischemia Rat Model. Cell Physiol Biochem (2014) 34(3):854-64. doi: 10.1159/000366304

55. Wang L, Sun L, Zhang Y, Wu H, Li C, Pan Z, et al. Ionic Mechanisms Underlying Action Potential Prolongation by Focal Cerebral Ischemia in Rat Ventricular Myocytes. Cell Physiol Biochem (2009) 23(4-6):305-16. doi: 10.1159/000218177

56. Sun L, Ai J, Wang N, Zhang R, Li J, Zhang T, et al. Cerebral Ischemia Elicits Aberration in Myocardium Contractile Function and Intracellular Calcium Handling. Cell Physiol Biochem (2010) 26(3):421-30. doi: 10.1159/000320584

57. Cechetto DF, Wilson JX, Smith KE, Wolski D, Silver MD, Hachinski VC. Autonomic and Myocardial Changes in Middle Cerebral Artery Occlusion: Stroke Models in the Rat. Brain Res (1989) 502(2):296-305. doi: 10.1016/ 0006-8993(89)90625-2

58. Butcher KS, Hachinski VC, Wilson JX, Guiraudon C, Cechetto DF. Cardiac and Sympathetic Effects of Middle Cerebral Artery Occlusion in the Spontaneously Hypertensive Rat. Brain Res (1993) 621(1):79-86. doi: 10.1016/0006-8993(93)90300-c

59. Sun L, Du J, Zhang G, Zhang Y, Pan G, Wang L, et al. Aberration of L-Type Calcium Channel in Cardiac Myocytes Is One of the Mechanisms of Arrhythmia Induced by Cerebral Ischemia. Cell Physiol Biochem (2008) 22 (1-4):147-56. doi: 10.1159/000149792

60. Hachinski VC, Oppenheimer SM, Wilson JX, Guiraudon C, Cechetto DF. Asymmetry of Sympathetic Consequences of Experimental Stroke. Arch Neurol (1992) 49(7):697-702. doi: 10.1001/archneur.1992.00530310039010 
61. Balint B, Jaremek V, Thorburn V, Whitehead SN, Sposato LA. Left Atrial Microvascular Endothelial Dysfunction, Myocardial Inflammation and Fibrosis After Selective Insular Cortex Ischemic Stroke. Int J Cardiol (2019) 292:148-55. doi: 10.1016/j.ijcard.2019.06.004

62. Hachinski VC, Smith KE, Silver MD, Gibson CJ, Ciriello J. Acute Myocardial and Plasma Catecholamine Changes in Experimental Stroke. Stroke (1986) 17(3):387-90. doi: 10.1161/01.str.17.3.387

63. Acosta SA, Mashkouri S, Nwokoye D, Lee JY, Borlongan CV. Chronic Inflammation and Apoptosis Propagate in Ischemic Cerebellum and Heart of Non-Human Primates. Oncotarget (2017) 8(61):102820-34. doi: 10.18632/oncotarget.18330

64. Ishikawa H, Tajiri N, Vasconcellos J, Kaneko Y, Mimura O, Dezawa M, et al. Ischemic Stroke Brain Sends Indirect Cell Death Signals to the Heart. Stroke (2013) 44(11):3175-82. doi: 10.1161/STROKEAHA.113.001714

65. Oppenheimer S. Cerebrogenic Cardiac Arrhythmias: Cortical Lateralization and Clinical Significance. Clin Auton Res (2006) 16(1):6-11. doi: 10.1007/ s10286-006-0276-0

66. Sposato LA, Cohen G, Wardlaw JM, Sandercock P, Lindley RI, Hachinski V, et al. Effect of Right Insular Involvement on Death and Functional Outcome After Acute Ischemic Stroke in the IST-3 Trial (Third International Stroke Trial). Stroke (2016) 47(12):2959-65. doi: 10.1161/STROKEAHA.116.014928

67. Xiong L, Leung HH, Chen XY, Han JH, Leung TW, Soo YO, et al. Comprehensive Assessment for Autonomic Dysfunction in Different Phases After Ischemic Stroke. Int J Stroke (2013) 8(8):645-51. doi: 10.1111/j.1747-4949.2012.00829.x

68. Tokgozoglu SL, Batur MK, Topcuoglu MA, Saribas O, Kes S, Oto A. Effects of Stroke Localization on Cardiac Autonomic Balance and Sudden Death. Stroke (1999) 30(7):1307-11. doi: 10.1161/01.str.30.7.1307

69. Andreis DT, Singer M. Catecholamines for Inflammatory Shock: A JekyllAnd-Hyde Conundrum. Intensive Care Med (2016) 42(9):1387-97. doi: 10.1007/s00134-016-4249-z

70. Rosmond R, Bjorntorp P. The Hypothalamic-Pituitary-Adrenal Axis Activity as a Predictor of Cardiovascular Disease, Type 2 Diabetes and Stroke. J Intern Med (2000) 247(2):188-97. doi: 10.1046/j.13652796.2000.00603.x

71. Costa VM, Carvalho F, Bastos ML, Carvalho RA, Carvalho M, Remiao F. Contribution of Catecholamine Reactive Intermediates and Oxidative Stress to the Pathologic Features of Heart Diseases. Curr Med Chem (2011) 18 (15):2272-314. doi: 10.2174/092986711795656081

72. Swaminathan PD, Purohit A, Hund TJ, Anderson ME. CalmodulinDependent Protein Kinase II: Linking Heart Failure and Arrhythmias. Circ Res (2012) 110(12):1661-77. doi: 10.1161/CIRCRESAHA.111.243956

73. Khan MU, Cheema Y, Shahbaz AU, Ahokas RA, Sun Y, Gerling IC, et al. Mitochondria Play a Central Role in Nonischemic Cardiomyocyte Necrosis: Common to Acute and Chronic Stressor States. Pflugers Arch (2012) 464 (1):123-31. doi: 10.1007/s00424-012-1079-x

74. Behonick GS, Novak MJ, Nealley EW, Baskin SI. Toxicology Update: The Cardiotoxicity of the Oxidative Stress Metabolites of Catecholamines (Aminochromes). J Appl Toxicol (2001) 21(Suppl 1):S15-22. doi: 10.1002/ jat.793

75. Zhang H, Xiong X, Liu J, Gu L, Li F, Wan Y, et al. Emulsified Isoflurane Protects Against Transient Focal Cerebral Ischemia Injury in Rats via the PI3K/Akt Signaling Pathway. Anesth Analg (2016) 122(5):1377-84. doi: 10.1213/ANE.0000000000001172

76. Kalita J, Bastia J, Bhoi SK, Misra UK. Systemic Inflammatory Response Syndrome Predicts Severity of Stroke and Outcome. J Stroke Cerebrovasc Dis (2015) 24(7):1640-8. doi: 10.1016/j.jstrokecerebrovasdis.2015.03.057

77. Chang J, Mancuso MR, Maier C, Liang X, Yuki K, Yang L, et al. Gpr124 Is Essential for Blood-Brain Barrier Integrity in Central Nervous System Disease. Nat Med (2017) 23(4):450-60. doi: 10.1038/nm.4309

78. Jayaraj RL, Azimullah S, Beiram R, Jalal FY, Rosenberg GA. Neuroinflammation: Friend and Foe for Ischemic Stroke. J Neuroinflamm (2019) 16(1):142. doi: 10.1186/s12974-019-1516-2

79. Offner H, Subramanian S, Parker SM, Afentoulis ME, Vandenbark AA, Hurn PD. Experimental Stroke Induces Massive, Rapid Activation of the Peripheral Immune System. J Cereb Blood Flow Metab (2006) 26(5):654-65. doi: $10.1038 /$ sj.jcbfm. 9600217
80. Urra X, Miro F, Chamorro A, Planas AM. Antigen-Specific Immune Reactions to Ischemic Stroke. Front Cell Neurosci (2014) 8:278. doi: $10.3389 /$ fncel.2014.00278

81. McCulloch L, Alfieri A, McColl BW. Experimental Stroke Differentially Affects Discrete Subpopulations of Splenic Macrophages. Front Immunol (2018) 9:1108. doi: 10.3389/fimmu.2018.01108

82. Benakis C, Brea D, Caballero S, Faraco G, Moore J, Murphy M, et al. Commensal Microbiota Affects Ischemic Stroke Outcome by Regulating Intestinal Gammadelta T Cells. Nat Med (2016) 22(5):516-23. doi: 10.1038/ nm.4068

83. Murray KN, Buggey HF, Denes A, Allan SM. Systemic Immune Activation Shapes Stroke Outcome. Mol Cell Neurosci (2013) 53:14-25. doi: 10.1016/ j.mcn.2012.09.004

84. Rossaint J, Margraf A, Zarbock A. Role of Platelets in Leukocyte Recruitment and Resolution of Inflammation. Front Immunol (2018) 9:2712. doi: 10.3389/fimmu.2018.02712

85. Zhou Z, Lindley RI, Radholm K, Jenkins B, Watson J, Perkovic V, et al. Canagliflozin and Stroke in Type 2 Diabetes Mellitus. Stroke (2019) 50 (2):396-404. doi: 10.1161/STROKEAHA.118.023009

86. Eriksson M, Carlberg B, Eliasson M. The Disparity in Long-Term Survival After a First Stroke in Patients With and Without Diabetes Persists: The Northern Sweden MONICA Study. Cerebrovasc Dis (2012) 34(2):153-60. doi: $10.1159 / 000339763$

87. Kang K, Park TH, Kim N, Jang MU, Park SS, Park JM, et al. Recurrent Stroke, Myocardial Infarction, and Major Vascular Events During the First Year After Acute Ischemic Stroke: The Multicenter Prospective Observational Study About Recurrence and Its Determinants After Acute Ischemic Stroke I. J Stroke Cerebrovasc Dis (2016) 25(3):656-64. doi: 10.1016/j.jstrokecerebrovasdis.2015.11.036

88. Devos J, Peeters A, Wittebole X, Hantson P. High-Dose Insulin Therapy for Neurogenic-Stunned Myocardium After Stroke. BMJ Case Rep (2012) 2012: bcr2012006620. doi: 10.1136/bcr-2012-006620

89. Tu Y, Guo C, Song F, Huo Y, Geng Y, Guo M, et al. Mild Hypothermia Alleviates Diabetes Aggravated Cerebral Ischemic Injury via Activating Autophagy and Inhibiting Pyroptosis. Brain Res Bull (2019) 150:1-12. doi: 10.1016/j.brainresbull.2019.05.003

90. Freeman R. Diabetic Autonomic Neuropathy. Handb Clin Neurol (2014) 126:63-79. doi: 10.1016/B978-0-444-53480-4.00006-0

91. Kuehl M, Stevens MJ. Cardiovascular Autonomic Neuropathies as Complications of Diabetes Mellitus. Nat Rev Endocrinol (2012) 8(7):40516. doi: $10.1038 /$ nrendo.2012.21

92. Thackeray JT, deKemp RA, Beanlands RS, DaSilva JN. Insulin Restores Myocardial Presynaptic Sympathetic Neuronal Integrity in Insulin-Resistant Diabetic Rats. J Nucl Cardiol (2013) 20(5):845-56. doi: 10.1007/s12350-013-9759-2

93. Zhang R, Gupta D, Albert SG. Pheochromocytoma as a Reversible Cause of Cardiomyopathy: Analysis and Review of the Literature. Int J Cardiol (2017) 249:319-23. doi: 10.1016/j.ijcard.2017.07.014

94. An D, Rodrigues B. Role of Changes in Cardiac Metabolism in Development of Diabetic Cardiomyopathy. Am J Physiol Heart Circ Physiol (2006) 291(4): H1489-506. doi: 10.1152/ajpheart.00278.2006

95. Schrauwen P, Hoeks J, Hesselink MK. Putative Function and Physiological Relevance of the Mitochondrial Uncoupling Protein-3: Involvement in Fatty Acid Metabolism? Prog Lipid Res (2006) 45(1):17-41. doi: 10.1016/ j.plipres.2005.11.001

96. Haley JM, Thackeray JT, Thorn SL, DaSilva JN. Cardiac Beta-Adrenoceptor Expression Is Reduced in Zucker Diabetic Fatty Rats as Type-2 Diabetes Progresses. PloS One (2015) 10(5):e0127581. doi: 10.1371/journal.pone.0127581

97. Fu Q, Hu Y, Wang Q, Liu Y, Li N, Xu B, et al. High-Fat Diet Induces Protein Kinase A and G-Protein Receptor Kinase Phosphorylation of Beta2 -Adrenergic Receptor and Impairs Cardiac Adrenergic Reserve in Animal Hearts. J Physiol (2017) 595(6):1973-86. doi: 10.1113/JP273314

98. Duncan BB, Schmidt MI. The Epidemiology of Low-Grade Chronic Systemic Inflammation and Type 2 Diabetes. Diabetes Technol Ther (2006) 8(1):7-17. doi: 10.1089/dia.2006.8.7

99. Mengel A, Ulm L, Hotter B, Harms H, Piper SK, Grittner U, et al. Biomarkers of Immune Capacity, Infection and Inflammation Are Associated With Poor Outcome and Mortality After Stroke - the 
PREDICT Study. BMC Neurol (2019) 19(1):148. doi: 10.1186/s12883-019$1375-6$

100. He A, Fang W, Zhao K, Wang Y, Li J, Yang C, et al. Mast Cell-Deficiency Protects Mice From Streptozotocin-Induced Diabetic Cardiomyopathy. Trans Res: J Lab Clin Med (2019) 208:1-14. doi: 10.1016/j.trsl.2019.01.005

101. Ritter L, Davidson L, Henry M, Davis-Gorman G, Morrison H, Frye JB, et al. Exaggerated Neutrophil-Mediated Reperfusion Injury After Ischemic Stroke in a Rodent Model of Type 2 Diabetes. Microcirculation (New York NY: 1994) (2011) 18(7):552-61. doi: 10.1111/j.1549-8719.2011.00115.x

102. Prasad S, Sajja RK, Naik P, Cucullo L. Diabetes Mellitus and Blood-Brain Barrier Dysfunction: An Overview. J Pharmacovigil (2014) 2(2):125. doi: 10.4172/2329-6887.1000125

103. Mangan MSJ, Olhava EJ, Roush WR, Seidel HM, Glick GD, Latz E. Targeting the NLRP3 Inflammasome in Inflammatory Diseases. Nat Rev Drug Discov (2018) 17(8):588-606. doi: 10.1038/nrd.2018.97

104. Yu ZW, Zhang J, Li X, Wang Y, Fu YH, Gao XY. A New Research Hot Spot: The Role of NLRP3 Inflammasome Activation, a Key Step in Pyroptosis, in Diabetes and Diabetic Complications. Life Sci (2020) 240:117138. doi: $10.1016 /$ j.lfs.2019.117138

105. Hong P, Gu RN, Li FX, Xiong XX, Liang WB, You ZJ, et al. NLRP3 Inflammasome as a Potential Treatment in Ischemic Stroke Concomitant With Diabetes. J Neuroinflamm (2019) 16(1):121. doi: 10.1186/s12974-0191498-0

106. Monnerat G, Alarcon ML, Vasconcellos LR, Hochman-Mendez C, Brasil G, Bassani RA, et al. Macrophage-Dependent IL-1beta Production Induces Cardiac Arrhythmias in Diabetic Mice. Nat Commun (2016) 7:13344. doi: $10.1038 /$ ncomms 13344

107. Suetomi T, Miyamoto S, Brown JH. Inflammation in Nonischemic Heart Disease: Initiation by Cardiomyocyte CaMKII and NLRP3 Inflammasome Signaling. Am J Physiol Heart Circ Physiol (2019) 317(5):H877-H90. doi: 10.1152/ajpheart.00223.2019

108. Li Q, Leng K, Liu Y, Sun H, Gao J, Ren Q, et al. The Impact of Hyperglycaemia on PKM2-Mediated NLRP3 Inflammasome/Stress Granule Signalling in Macrophages and Its Correlation With Plaque Vulnerability: An In Vivo and In Vitro Study. Metabol: Clin Exp (2020) 107:154231. doi: 10.1016/j.metabol.2020.154231

109. Toldo S, Mezzaroma E, McGeough MD, Pena CA, Marchetti C, Sonnino C, et al. Independent Roles of the Priming and the Triggering of the NLRP3 Inflammasome in the Heart. Cardiovasc Res (2015) 105(2):203-12. doi: $10.1093 / \mathrm{cvr} / \mathrm{cvu} 259$

110. Epelman S, Lavine KJ, Beaudin AE, Sojka DK, Carrero JA, Calderon B, et al. Embryonic and Adult-Derived Resident Cardiac Macrophages Are Maintained Through Distinct Mechanisms at Steady State and During Inflammation. Immunity (2014) 40(1):91-104. doi: 10.1016/j.immuni.2013.11.019

111. Yao C, Veleva T, Scott L Jr, Cao S, Li L, Chen G, et al. Enhanced Cardiomyocyte NLRP3 Inflammasome Signaling Promotes Atrial Fibrillation. Circulation (2018) 138(20):2227-42. doi: 10.1161/CIRCULATIONAHA.118.035202
112. Bracey NA, Gershkovich B, Chun J, Vilaysane A, Meijndert HC, Wright JR $\mathrm{Jr}$, et al. Mitochondrial NLRP3 Protein Induces Reactive Oxygen Species to Promote Smad Protein Signaling and Fibrosis Independent From the Inflammasome. J Biol Chem (2014) 289(28):19571-84. doi: 10.1074/ jbc.M114.550624

113. Bao J, Sun T, Yue Y, Xiong S. Macrophage NLRP3 Inflammasome Activated by CVB3 Capsid Proteins Contributes to the Development of Viral Myocarditis. Mol Immunol (2019) 114:41-8. doi: 10.1016/j.molimm. 2019.07.012

114. Paramel Varghese G, Folkersen L, Strawbridge RJ, Halvorsen B, Yndestad A, Ranheim T, et al. NLRP3 Inflammasome Expression and Activation in Human Atherosclerosis. J Am Heart Assoc (2016) 5(5):e003031. doi: 10.1161/JAHA.115.003031

115. Xu JM, Shi GP. Emerging Role of Mast Cells and Macrophages in Cardiovascular and Metabolic Diseases. Endocr Rev (2012) 33(1):71-108. doi: 10.1210/er.2011-0013

116. Deng Q, Geng Y, Zhao L, Li R, Zhang Z, Li K, et al. NLRP3 Inflammasomes in Macrophages Drive Colorectal Cancer Metastasis to the Liver. Cancer Lett (2019) 442:21-30. doi: 10.1016/j.canlet.2018.10.030

117. Zhao P, Zhou W, Zhang Y, Li J, Zhao Y, Pan L, et al. Aminooxyacetic Acid Attenuates Post-Infarct Cardiac Dysfunction by Balancing Macrophage Polarization Through Modulating Macrophage Metabolism in Mice. J Cell Mol Med (2020) 24(4):2593-609. doi: 10.1111/jcmm.14972

118. Fukuhara S, Tanigaki R, Kimura KI, Kataoka T. Kujigamberol Interferes With Pro-Inflammatory Cytokine-Induced Expression of and N-Glycan Modifications to Cell Adhesion Molecules at Different Stages in Human Umbilical Vein Endothelial Cells. Int Immunopharmacol (2018) 62:313-25. doi: 10.1016/j.intimp.2018.07.016

119. Hansen PR. Role of Neutrophils in Myocardial Ischemia and Reperfusion. Circulation (1995) 91(6):1872-85. doi: 10.1161/01.cir.91.6.1872

Conflict of Interest: The authors declare that the research was conducted in the absence of any commercial or financial relationships that could be construed as a potential conflict of interest.

Publisher's Note: All claims expressed in this article are solely those of the authors and do not necessarily represent those of their affiliated organizations, or those of the publisher, the editors and the reviewers. Any product that may be evaluated in this article, or claim that may be made by its manufacturer, is not guaranteed or endorsed by the publisher.

Copyright ( 2021 Lin, Li, Zhang, You, Xu, Liang and Zhang. This is an open-access article distributed under the terms of the Creative Commons Attribution License (CC BY). The use, distribution or reproduction in other forums is permitted, provided the original author(s) and the copyright owner(s) are credited and that the original publication in this journal is cited, in accordance with accepted academic practice. No use, distribution or reproduction is permitted which does not comply with these terms. 